


\section{GEORG REIMER}

Verlagsbuchbandlung

\section{BERLIN W 35}

Lützowstraße 107-8.

\section{Griechische Philosophie im alten Testament.}

Eine Einleitung in die Psalmen- und Weisheitsliteratur von

M. Fri edländer.

Geheftet M. 5.40.

\section{Das Tier Jehovahs.}

Ein kulturhistorischer Essay

von

Ernst Heilborn.

Preis kartoniert M. 3.-.

Inhalt: I. Der Mensch und die Tiere. II. Der Gott und die Tiere.

III. Das Erwachen des Naturgefühls. IV. Die Phantastik des Naturgefühls. V. Die gestaltende Phantasie.

Beiträge zur Geschichte der griechischen Philosophie und Religion

P. Wendland und 0. Kern.

Geheftet M. 2.-.

\section{Griechen und Semiten}

auf dem Isthmus von Korinth.

Religionsgeschichtliche Untersuchungen von

Mit einer Abbildung.

Ernst Maass.

\section{Lexicon Syropalaestinum}

$$
\text { Adiuvante }
$$

Academia Litterarum Regia Borussica

Edidit

Fridericus Schnlthess.

Gebeftet M. 10.-, gebunden M. 12.- 


\title{
DIE RELIGIÖSEN BEWEGUNGEN INNERHALB DES JUDENTUMS IM ZEITALTER JESU
}

vON

\author{
M. FRIEDLÄNDER
}

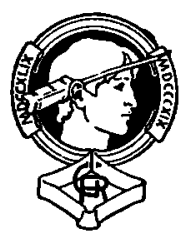

B E R L I N

DRUCK UND VERLAG VON GEORG REIMER 
